\title{
4-Hydroxytamoxifen is a potent inhibitor of the mitochondrial permeability transition
}

\author{
Carla M.P. Cardoso ${ }^{\mathrm{a}, \mathrm{b}}$, Leonor M. Almeida ${ }^{\mathrm{a}, \mathrm{b}}$, José B.A. Custódio ${ }^{\mathrm{a}, \mathrm{b}, *}$ \\ ${ }^{a}$ Laboratório de Bioquímica, Faculdade de Farmácia, Couraça dos Apóstolos, 51, r/c, Coimbra 3000-295, Portugal \\ ${ }^{\mathrm{b}}$ Centro de Neurociencias de Coimbra, Universidade de Coimbra, Portugal
}

Received in revised form 17 April 2002; accepted 18 April 2002

\begin{abstract}
The effects of 4-hydroxytamoxifen (OHTAM), the major active metabolite of the antiestrogen tamoxifen used in the breast cancer therapy, were studied on the mitochondrial permeability transition (MPT) and bioenergetic functions of mitochondria to evaluate the mechanisms underlying the cell death and toxic effects. The MPT was induced in vitro by incubating rat liver mitochondria with $1 \mathrm{mM}$ inorganic phosphate plus $\mathrm{Ca}^{2+}$ and with tert-butyl hydroperoxide. OHTAM provides protection against the $\mathrm{Ca}^{2+}$-induced mitochondrial swelling, depolarization of the mitochondrial membrane potential $(\Delta \Psi)$, loss of electrophoretic $\mathrm{Ca}^{2+}$ uptake capacity and uncoupling of respiration, similarly to cyclosporine A. The concentrations of OHTAM used do not significantly affect $\Delta \Psi$, respiratory control and adenosine diphosphate/oxygen ratios and induce repolarization and $\mathrm{Ca}^{2+}$ re-uptake, suggesting that such inhibitory effects of OHTAM were due to the prevention of the MPT induction and not due to the inhibition of the mitochondrial $\mathrm{Ca}^{2+}$ uniporter. Since the MPT induction has been linked to an oxidized shift in the mitochondrial redox state and/or increase in the generation of reactive oxygen species, the MPT prevention by OHTAM may be related to its high antioxidant capacity. (C) 2002 Elsevier Science B.V. and Mitochondria Research Society. All rights reserved.
\end{abstract}

Keywords: 4-Hydroxytamoxifen; Anticancer drug; Breast cancer; Mitochondrial bioenergetics; Mitochondrial permeability transition; Oxidative stress

\section{Introduction}

4-Hydroxytamoxifen (OHTAM) is the major active metabolite of the antiestrogenic drug tamoxifen (TAM) used in the chemotherapy and prevention of breast cancer (Jordan, 1990). OHTAM have been reported to be pharmacologically active, playing an important role in the therapeutic activity and side effects of TAM (Kemp et al., 1983). The antiestrogenic and antiproliferative activities of OHTAM in

\footnotetext{
* Corresponding author. Tel.: +351-239-852564; fax: +351-239852569.

E-mail address: custodio@ci.uc.pt (J.B.A. Custódio).
}

vitro are much stronger as compared to TAM (Borgna and Rochefort, 1981), but the pharmacological relevance of OHTAM has been questioned (McCague et al., 1990) due to its low serum concentrations (Lien et al., 1987; MacCallum et al., 1996). However, the strong affinity of OHTAM for biomembrane proteins and its higher partitioning in the lipid bilayer as compared to TAM (Custódio et al., 1991), perturbing the membrane lipid-protein interface (Custódio et al., 1993), suggest that OHTAM may accumulate in tissues, reaching the required effective concentrations in the tissues for its cytotoxic effects, as described by Lien et al. (1991). Moreover, it has been established 
that OHTAM does not induce proliferative or neoplastic lesions, genotoxicity (Sauvez et al., 1999), erythrocyte hemolysis (Cruz Silva et al., 2001) and it is pharmacologically well tolerated as compared to TAM (Sauvez et al., 1999) whose therapeutical use is now questionable. In fact TAM may increase the incidence of liver (Williams et al., 1993) and endometrial (Fisher et al., 1994) cancers, induction of genotoxicity (Davies et al., 1995), hemolytic anemia (Ching et al., 1992; Suwalsky et al., 1998; Cruz Silva et al., 2000), hepatic and cardiac lesions (Kargacin et al., 2000), suggesting OHTAM as a more advantageous drug in the breast cancer therapy. The use of OHTAM in malignant and non-malignant breast cancer diseases by topical application is undergoing clinical evaluation as an alternative route to TAM treatment (Mauvais-Jarvis et al., 1986) and pharmacological studies to evaluate differences between the percutaneous and the oral routes have been performed (Pujol et al., 1995; Sauvez et al., 1999). Therefore, studies of cytotoxic effects of OHTAM and the underlying molecular mechanisms are required to assure a safe and appropriate therapeutical administration of the drug.

Mitochondria have been implicated as an important subcellular site of damage induced by several xenobiotics and interference on mitochondrial bioenergetics is known to be involved in the process of lethal cell injury induced by xenobiotics, leading to cellular ATP depletion and cell death (Wallace et al., 1997; Wallace and Starkov, 2000). Additionally, the mitochondrial permeability transition (MPT) has been implicated in the mitochondrial and cellular $\mathrm{Ca}^{2+}$ homeostasis, in cell defense (Bernardi, 1996) and in the mechanisms of toxic tissue injury caused by different compounds, the majority of which are oxidants (Zoratti and Szabo, 1995; Wallace et al., 1997). Besides the proposed role of the MPT in the cell life, different studies have provided further support for the central role of the MPT in various intracellular signalling pathways including apoptotic program (Bernardi, 1996; Ichas and Mazat, 1998). Since prooxidants, that oxidize mitochondrial membrane protein sulfhydryl groups, mitochondrial matrix GSH and nucleotides $[\mathrm{NAD}(\mathrm{P}) \mathrm{H}]$, are known to induce the MPT (Petronilli et al., 1994; Constantini et al., 1996), OHTAM, owing to its antioxidant properties (Custódio et al., 1994), may inhibit MPT.
Therefore, the aim of this work was to study the effects of OHTAM on both mitochondrial bioenergetics and MPT to contribute to the understanding of the molecular mechanisms underlying the action and cytotoxicity of OHTAM. Some of these data have been presented elsewhere in preliminary form (Cardoso et al., 2000).

\section{Materials and methods}

\subsection{Chemicals}

4-Hydroxytamoxifen (OHTAM), 4-(2-hydroxymethyl)-1-piperazineethanesulfonic acid (HEPES), bovine serum albumin (BSA), cyclosporine A (CyA), oligomycin and tert-butyl hydroperoxide $70 \%$ aqueous solution $(t-\mathrm{BuOOH})$ were purchased from Sigma Chemical Co. (St. Louis, MO). Ethylene glycolbis(b-aminoethyl ether) $N_{N} N^{\prime} N^{\prime}$-tetraacetic acid (EGTA), tetraphenylphosphonium $\left(\mathrm{TPP}^{+}\right)$and sucrose were from MercK (Darmstadt, Germany). All the chemicals were commercial products of the highest purity grade available.

\subsection{Rat liver mitochondria}

Mitochondria were isolated from the liver of rats (Wistar) of either sex, fasted overnight, by differential centrifugation as described elsewhere (Custódio et al., 1998). Animals were killed by decapitation and the liver was quickly homogenized. The homogenate was prepared at $4^{\circ} \mathrm{C}$ in $250 \mathrm{mM}$ sucrose, $10 \mathrm{mM}$ HEPES (pH 7.4), 1 mM EGTA and 0.1\% BSA free fatty acid, which was added just prior to use, and centrifuged for $10 \mathrm{~min}$ at $1200 \times g$. The mitochondrial pellet was resuspended in the washing medium, adjusted to $\mathrm{pH}$ 7.2 in the absence of EGTA and BSA, and mitochondria washed twice were recovered from the supernatant at $10,000 \times g$ for $10 \mathrm{~min}$. Mitochondrial protein was measured by the method of Biuret (Gornall et al., 1949) with BSA as protein standard.

\subsection{Standard incubation procedure}

The experiments were carried out at $25^{\circ} \mathrm{C}$ in a standard reaction medium containing $200 \mathrm{mM}$ sucrose,

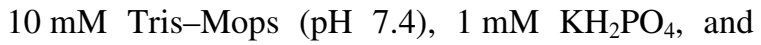
$10 \mu \mathrm{M}$ EGTA, supplemented with $2 \mu \mathrm{M}$ rotenone 
and $0.5 \mu \mathrm{g}$ oligomycin/ml. OHTAM was added in aliquots of a stock ethanolic solution to the reaction medium after protein addition and incubated for $3 \mathrm{~min}$ before starting the reactions. Other additions were as indicated in the figure legends. The results shown represent typical recordings from experiments of at least three different mitochondrial preparations.

\subsection{Mitochondrial swelling}

Changes in mitochondrial osmotic volume were monitored by the decrease in apparent absorbance (light-scattering) at $540 \mathrm{~nm}$, with a Perkin-Elmer Lambda 6 UV/VIS spectrophotometer computer controlled (Norwalk, USA). Mitochondria were suspended at $0.5 \mathrm{mg}$ protein $/ \mathrm{ml}$ in $2 \mathrm{ml}$ of standard reaction medium and the reaction was started with $5 \mathrm{mM}$ succinate. $\mathrm{CaCl}_{2}(140 \mathrm{nmol} / \mathrm{mg}$ protein) was added 2 min after energization of mitochondria with succinate. In some of the experiments, the standard reaction medium was supplemented with $100 \mu \mathrm{M} t$ $\mathrm{BuOOH}$ before energization of mitochondria at $25^{\circ} \mathrm{C}$ and $\mathrm{Ca}^{2+}$ addition $(100 \mathrm{nmol} / \mathrm{mg}$ protein). Where indicated, OHTAM or CyA in ethanolic solutions was added before or after starting the reactions.

\subsection{Mitochondrial membrane potential $(\Delta \Psi)$}

The mitochondrial membrane potential $(\Delta \Psi)$ was monitored by evaluating transmembrane distribution of tetraphenylphosphonium $\left(\mathrm{TPP}^{+}\right)$with an ion-selective electrode prepared according to Kamo et al. (1979) using a $\mathrm{Ag} / \mathrm{AgCl}_{2}$ electrode as reference (model MI 402; Microelectrodes, Inc., Bedford, $\mathrm{NH})$. Reactions were carried out in an open vessel with magnetic stirring in $2 \mathrm{ml}$ of standard reaction medium supplemented with $4 \mu \mathrm{M} \mathrm{TPP}{ }^{+}$. The experiments were started by adding $5 \mathrm{mM}$ succinate to mitochondria in suspension at $0.5 \mathrm{mg}$ protein/ $\mathrm{ml}$ and $\mathrm{CaCl}_{2} \quad(140 \mathrm{nmol} / \mathrm{mg}$ protein $)$ was added after steady-state distribution of $\mathrm{TPP}^{+}$. Membrane potential was estimated from the decrease of $\mathrm{TPP}^{+}$concentration in the medium as described elsewhere (Kamo et al., 1979; Moreno and Madeira, 1991). OHTAM and CyA were incubated 2 min before succinate or after mitochondrial loading with $\mathrm{Ca}^{2+}$ as indicated in the figure legends.

\subsection{Mitochondrial oxygen consumption and membrane potential measurements}

Mitochondria ( $1 \mathrm{mg} / \mathrm{ml})$ were suspended in respiratory medium containing $130 \mathrm{mM}$ sucrose, $50 \mathrm{mM}$ $\mathrm{KCl}, \quad 2.5 \mathrm{mM} \quad \mathrm{MgCl}_{2}, 2.5 \mathrm{mM} \quad \mathrm{KH}_{2} \mathrm{PO}_{4}, \quad 5 \mathrm{mM}$ HEPES and $0.1 \mathrm{mM}$ EGTA supplemented with $2 \mu \mathrm{M}$ rotenone and $4 \mu \mathrm{M} \mathrm{TPP}$. The incubations were conducted at $25^{\circ} \mathrm{C}$ in a closed reaction chamber with constant stirring. Oxygen tension was monitored polarographically with a Clark-type electrode (Estrabrook, 1967) and $\Delta \Psi$ was measured with a $\mathrm{TPP}^{+}$electrode, as described before, inserted through an airtight port into the oxygen vessel to monitor oxygen consumption and $\Delta \Psi$ simultaneously. The reactions were initiated by adding succinate to a final concentration of $5 \mathrm{mM}$. After reaching the maximum $\Delta \Psi$, ADP $(150 \mathrm{nmol})$ was added to initiate state 3 respiration and oxygen tension was monitored continuously until state 4 respiration was resumed.

\subsection{Mitochondrial $\mathrm{Ca}^{2+}$ fluxes}

Mitochondrial $\mathrm{Ca}^{2+}$ fluxes were measured by monitoring the changes in $\mathrm{Ca}^{2+}$ concentration in the reaction medium using a $\mathrm{Ca}^{2+}$-selective electrode (Madeira, 1975; Moreno and Madeira, 1991). The reactions were conducted in an open vessel with magnetic stirring in $2 \mathrm{ml}$ of the reaction medium containing $200 \mathrm{mM}$ sucrose, $10 \mathrm{mM}$ Tris-Mops (pH 7.4), $1 \mathrm{mM} \mathrm{KH_{2 }} \mathrm{PO}_{4}$, and $10 \mathrm{mM}$ EGTA, supplemented with $2 \mu \mathrm{M}$ rotenone and $1 \mu \mathrm{g}$ oligomycin. Mitochondria $(0.5 \mathrm{mg}$ protein $/ \mathrm{ml})$ were energized with $5 \mathrm{mM}$ succinate after $2 \mathrm{~min}$ of $\mathrm{Ca}^{2+}$ addition in the absence (control) and presence of OHTAM and CyA. In other experiments, OHTAM and CyA were added at different times after adding $\mathrm{Ca}^{2+}$ to the succinateenergized mitochondria.

\section{Results}

Mitochondria energized with succinate in the presence of $\mathrm{Ca}^{2+}(140 \mathrm{nmol} / \mathrm{mg}$ protein) and $1 \mathrm{mM}$ inorganic phosphate $\left(\mathrm{P}_{\mathrm{i}}\right)$ undergo a rapid and large decrease in the absorbance at $540 \mathrm{~nm}$ which suggests complete swelling of mitochondria (Fig. 1A, Control). This extensive effect is completely prevented by preincubating mitochondria with 10 and $20 \mathrm{nmol}$ 

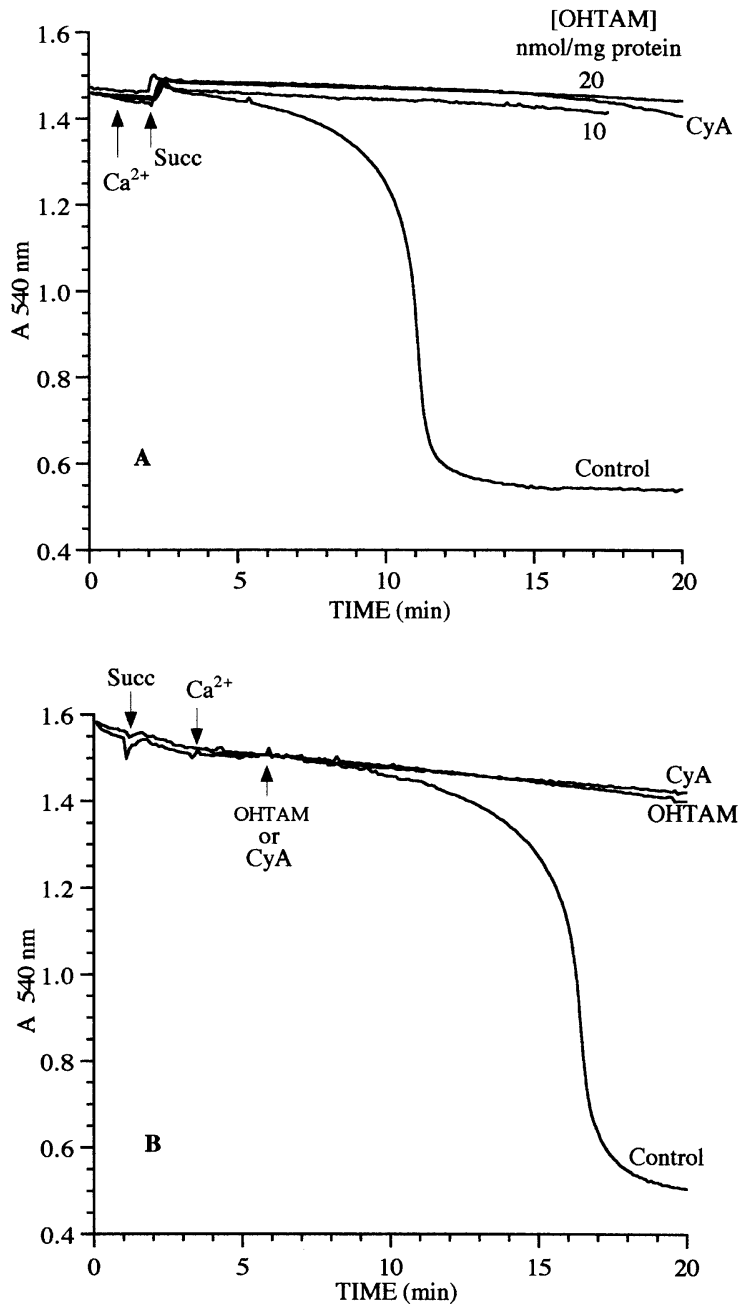

Fig. 1. Inhibition of mitochondrial swelling by OHTAM. Rat liver mitochondria incubated at $0.5 \mathrm{mg}$ protein $/ \mathrm{ml}$ in $200 \mathrm{mM}$ sucrose$10 \mathrm{mM}$ Tris-Mops (pH 7.4), 1 mM KH${ }_{2} \mathrm{PO}_{4}, 10 \mu \mathrm{M}$ EGTA, supplemented with $2 \mu \mathrm{M}$ rotenone and $0.5 \mu \mathrm{g} / \mathrm{ml}$ oligomycin were energized with $5 \mathrm{mM}$ succinate at $25^{\circ} \mathrm{C}$. Light scattering was monitored continuously at $540 \mathrm{~nm}$ for assessing changes in mitochondrial volume. Where indicated, OHTAM (10 and $20 \mathrm{nmol} / \mathrm{mg}$ protein) or CyA $(1.7 \mathrm{nmol} / \mathrm{mg}$ protein) was included in the reaction medium just prior to adding $\mathrm{Ca}^{2+}(140 \mathrm{nmol} / \mathrm{mg}$ protein) (A) and after succinate and $\mathrm{Ca}^{2+}$ addition (B). Control refers to the experiment in the absence of either OHTAM or CyA.

OHTAM/mg protein, similarly to what happens with CyA $(1.7 \mathrm{nmol} / \mathrm{mg}$ protein), a specific and potent inhibitor of the MPT (Broekemeier et al., 1989), suggesting that OHTAM completely protects against the $\mathrm{Ca}^{2+}$-dependent MPT.
The protection of mitochondrial swelling afforded by OHTAM is observed either when the drug (20 nmol OHTAM/mg protein) is added before (Fig. 1A) or after (Fig. 1B) energization of mitochondria with succinate and loading with $\mathrm{Ca}^{2+}$, providing evidence that OHTAM neither causes membrane depolarization nor interferes with the $\mathrm{Ca}^{2+}$ uniporter.

The inhibition of the $\mathrm{Ca}^{2+}$ plus $\mathrm{P}_{\mathrm{i}}$-induced mitochondrial swelling by OHTAM is a function of elapsed time, so that the longer the delay in adding OHTAM, the less pronounced is the inhibition of swelling (Fig. 2, traces 1-5), demonstrating that OHTAM is very efficient as inhibitor of the progressive swelling of isolated mitochondria in suspension, induced by the combination of $\mathrm{Ca}^{2+}$ plus $\mathrm{P}_{\mathrm{i}}$.

The inhibitory effect of OHTAM on induction of the MPT by $\mathrm{Ca}^{2+}$ plus $\mathrm{P}_{\mathrm{i}}$ is also demonstrated by the fact that OHTAM prevents the $\mathrm{Ca}^{2+}$-induced depolarization of mitochondrial membrane potential $(\Delta \Psi)$ associated with MPT induction (Fig. 3). The addition of $\mathrm{Ca}^{2+}(180 \mathrm{nmol} / \mathrm{mg}$ protein) causes a transient depolarization with $\Delta \Psi$ returning to near $205 \mathrm{mV}$ within $1.5 \mathrm{~min}$. The repolarization of $\Delta \Psi$ after $\mathrm{Ca}^{2+}$

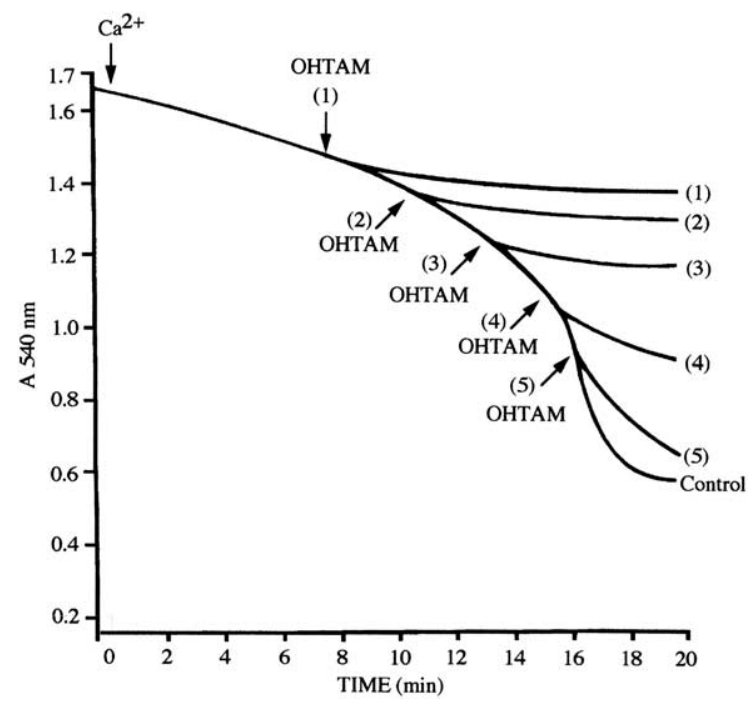

Fig. 2. Time-dependent inhibition of mitochondrial swelling by OHTAM. Experimental conditions were identical to those described in the legend to Fig. 1, except that OHTAM $(20 \mathrm{nmol} / \mathrm{mg}$ protein) was added at different times after adding $\mathrm{Ca}^{2+}(140 \mathrm{nmol} / \mathrm{mg}$ protein) to the succinate-energized mitochondria. The control trace refers to the experiment with $\mathrm{Ca}^{2+}+\mathrm{P}_{\mathrm{i}}$ alone. 


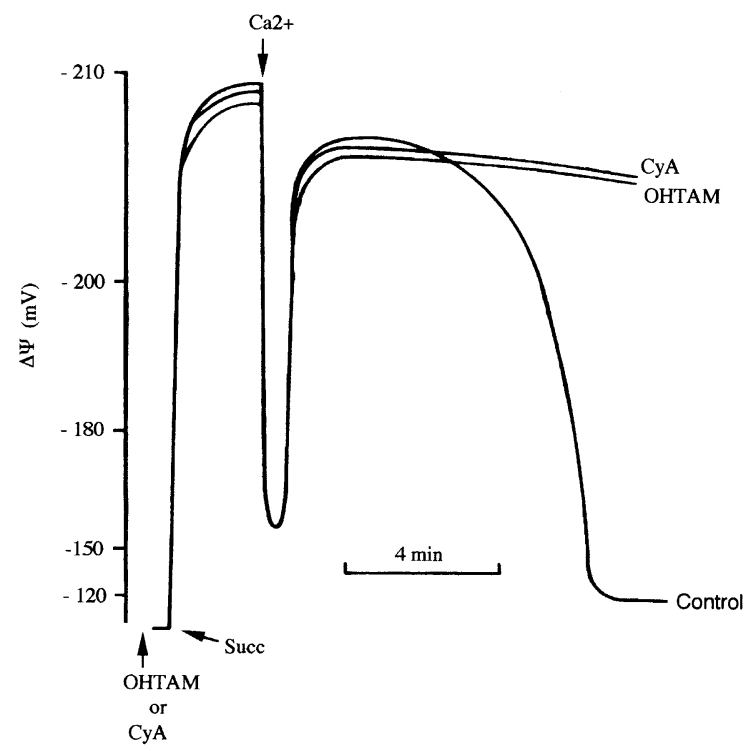

Fig. 3. Effects of OHTAM on mitochondrial depolarization associated with MPT induction. Mitochondria (1 mg) suspended in standard reaction medium supplemented with $4 \mu \mathrm{M} \mathrm{TPP}^{+}$were preincubated for $3 \mathrm{~min}$ at $25^{\circ} \mathrm{C}$ in the absence (Control) and in the presence of either $20 \mathrm{nmol}$ OHTAM/mg protein or $1.7 \mathrm{nmol} / \mathrm{mg}$ protein CyA. The reactions were started with $5 \mathrm{mM}$ succinate and $\mathrm{Ca}^{2+}(140 \mathrm{nmol} / \mathrm{mg}$ protein) was added after steady state distribution of $\mathrm{TPP}^{+}$. Mitochondrial membrane potential $(\Delta \Psi)$ was monitored with a $\mathrm{TPP}^{+}$-sensitive electrode. The traces are typical of several experiments with different mitochondrial preparations.

accumulation is followed by a dramatic and irreversible depolarization of mitochondria over the course of the next $10 \mathrm{~min}$ (Fig. 3, control). Pre-incubating with antiestrogen OHTAM prior to adding succinate and $\mathrm{Ca}^{2+}$ affords complete protection against the $\mathrm{Ca}^{2+}$-induced irreversible depolarization of $\Delta \Psi$ (Fig. 3) similarly to CyA. Under these conditions, the $\mathrm{Ca}^{2+}$ uptake still causes a transient depolarization of $\Delta \Psi$ and mitochondria have capacity to sustain this membrane potential. Moreover and similarly to what is observed for mitochondrial swelling (Fig. 2), the effect of OHTAM in preventing the $\mathrm{Ca}^{2+}$-induced depolarization of $\Delta \Psi$ is dependent on the time elapsed after the addition of $\mathrm{Ca}^{2+}$ (Fig. 4). In fact, OHTAM reverses the $\mathrm{Ca}^{2+}$-induced membrane depolarization if added before the complete depolarization of mitochondria (Fig. 4, traces 1-4).

Further evidence that OHTAM inhibits the $\mathrm{Ca}^{2+}$ induced MPT is provided by the fact that it also

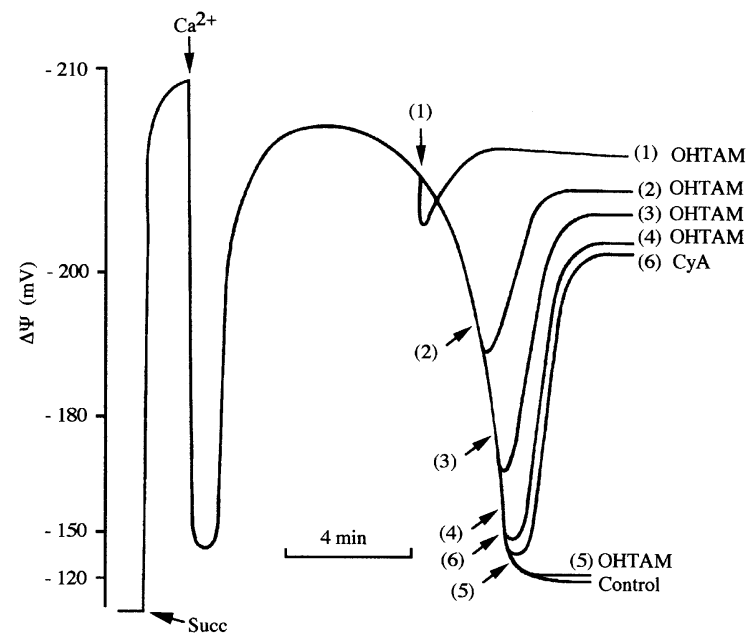

Fig. 4. OHTAM induces repolarization after MPT induced by $\mathrm{Ca}^{2+}$ $\left(140 \mathrm{nmol} / \mathrm{mg}\right.$ protein) plus $1 \mathrm{mM} \mathrm{P}_{\mathrm{i}}$. The reactions were carried out as described for Fig. 3 except that OHTAM ( $20 \mathrm{nmol} / \mathrm{mg}$ protein) was added at different times after mitochondria $\mathrm{Ca}^{2+}$ accumulation (traces 1-4). The control trace corresponds to $\mathrm{Ca}^{2+}+\mathrm{P}_{\mathrm{i}}$ alone and the trace labeled CyA (6) represents the effect of $1.7 \mathrm{nmol} / \mathrm{mg}$ protein CyA added late during the pore transition, as indicated by the corresponding labeled arrow. Mitochondrial depolarization and repolarization were monitored by following $\Delta \Psi$ with a $\mathrm{TPP}^{+}$-selective electrode. All the traces are representative of several separate experiments.

prevents the release of mitochondrial loaded $\mathrm{Ca}^{2+}$ (Fig. 5). Mitochondria energized with succinate release the accumulated $\mathrm{Ca}^{2+}$ within about $15 \mathrm{~min}$ (Fig. 5, control) but co-incubation with OHTAM prevents this effect similarly to what is observed with CyA, enabling mitochondria with the capacity to accumulate and sustain the added $\mathrm{Ca}^{2+}$. Moreover, adding OHTAM during the time course of the MPT reverses the $\mathrm{Ca}^{2+}$ release (Fig. 6, traces 1-3) in agreement with the repolarization effect (Fig. 4). The effect of OHTAM in inducing the $\mathrm{Ca}^{2+}$ re-uptake is dependent on the time elapsed after the addition of $\mathrm{Ca}^{2+}$ (Fig. 6), as observed for mitochondrial swelling (Fig. 2). OHTAM induces $\mathrm{Ca}^{2+}$ re-uptake if added before the complete release of the cation from mitochondria (Fig. 6, traces 1-3). CyA, even when added late in the reaction, causes total re-uptake of the released $\mathrm{Ca}^{2+}$ (Fig. 6, CyA trace). However, unlike to what was observed in the $\Delta \Psi$ repolarization (Fig. 4) and for $\mathrm{Ca}^{2+}$ re-uptake (Fig. 6), OHTAM does not reverse the changes occurred on the mitochondrial 


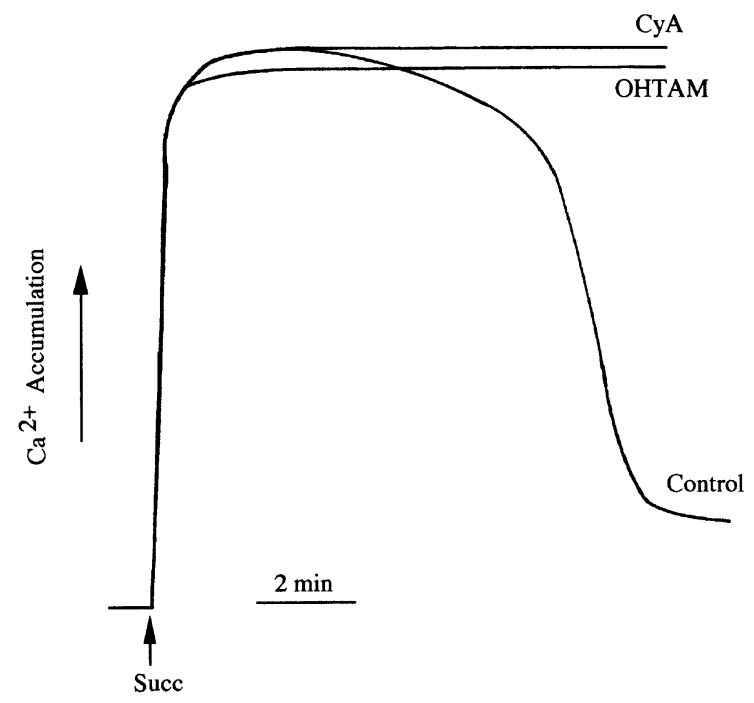

Fig. 5. Inhibitory effect of OHTAM on mitochondrial $\mathrm{Ca}^{2+}$ release related to MPT induction. Mitochondria (1 mg) suspended in $2 \mathrm{ml}$ of standard reaction medium containing $200 \mathrm{mM}$ sucrose- $10 \mathrm{mM}$ Tris-Mops (pH 7.4)-1 mM KH $\mathrm{PO}_{4}-10 \mu \mathrm{M}$ EGTA, supplemented with $2 \mu \mathrm{M}$ rotenone and $0.5 \mu \mathrm{g} / \mathrm{ml}$ oligomycin at $25^{\circ} \mathrm{C}$, were energized with $5 \mathrm{mM}$ succinate in the absence (control) and presence of $20 \mathrm{nmol} \mathrm{OHTAM} / \mathrm{mg}$ protein or $1.7 \mathrm{nmol} / \mathrm{mg}$ protein CyA prior to adding $180 \mathrm{nmol} \mathrm{Ca}{ }^{2+} / \mathrm{mg}$ protein. The uptake of $\mathrm{Ca}^{2+}$ and release of sequestered $\mathrm{Ca}^{2+}$ by mitochondria were monitored using a $\mathrm{Ca}^{2+}$ selective electrode. The traces are representative of several separate experiments.

volume (Fig. 2), similarly to CyA. In fact, swelling itself is thought to occur because matrix proteins are slow to equilibrate through the permeability defect as compared to smaller solutes. This creates a colloid osmotic pressure imbalance which drives the entrance of water, resulting in dilution of the matrix with consequent decrease in absorbance. The population of mitochondria that have already undergone this process have been equilibrated with water and solutes and this is not reversed.

To clarify the mechanisms by which OHTAM inhibits the MPT, its effects on MPT induced by $t$-BuOOH and $\mathrm{Ca}^{2+}$ were studied. Incubation of succinate-energized mitochondria with $\mathrm{Ca}^{2+}(100 \mathrm{nmol})$ in the presence of $100 \mu \mathrm{M} t$-BuOOH causes a large-amplitude decrease in light scattering (Fig. 7, Control) indicating the occurrence of mitochondrial swelling due to MPT induction since this effect is prevented by CyA (Fig. 7A). Pre-incubation with OHTAM (20 nmol/mg protein) protects mitochondria against mitochondrial swelling induced by the combination of $\mathrm{Ca}^{2+}$ plus $t$ $\mathrm{BuOOH}$ (Fig. 7A, OHTAM trace) similarly to what happens with the swelling induced by $\mathrm{Ca}^{2+}$ plus $\mathrm{P}_{\mathrm{i}}$ (Fig. 1A). Therefore, $t$-BuOOH increases the sensitivity of mitochondria to $\mathrm{Ca}^{2+}$-induced swelling (Fig. 7A, control), since $\mathrm{Ca}^{2+}$ alone (Fig. 7A, $\mathrm{Ca}^{2+}$ trace) or $t$ $\mathrm{BuOOH}$ alone (Fig. 7A, $t$-BuOOH trace) in mitochondrial suspensions does not cause any decrease in the absorbance. The inhibitory effect of OHTAM on MPT induced by $t$-BuOOH plus $\mathrm{Ca}^{2+}$ is also a function of elapsed time, the longer OHTAM is added to the mitochondrial suspension, the less pronounced is the inhibition of swelling (Fig. 7B). OHTAM inhibits the continuance of swelling induced by $\mathrm{Ca}^{2+}$ plus $t$ $\mathrm{BuOOH}$, similarly to what happens with the swelling induced by the combination of $\mathrm{Ca}^{2+}$ plus $\mathrm{P}_{\mathrm{i}}$ in mitochondrial suspensions. CyA added during the progression of the swelling arrests the continuance of this phenomenon, as in the case of $\mathrm{Ca}^{2+}$ plus $\mathrm{P}_{\mathrm{i}}$ induced swelling (data not shown).

In order to verify whether the OHTAM concentra-

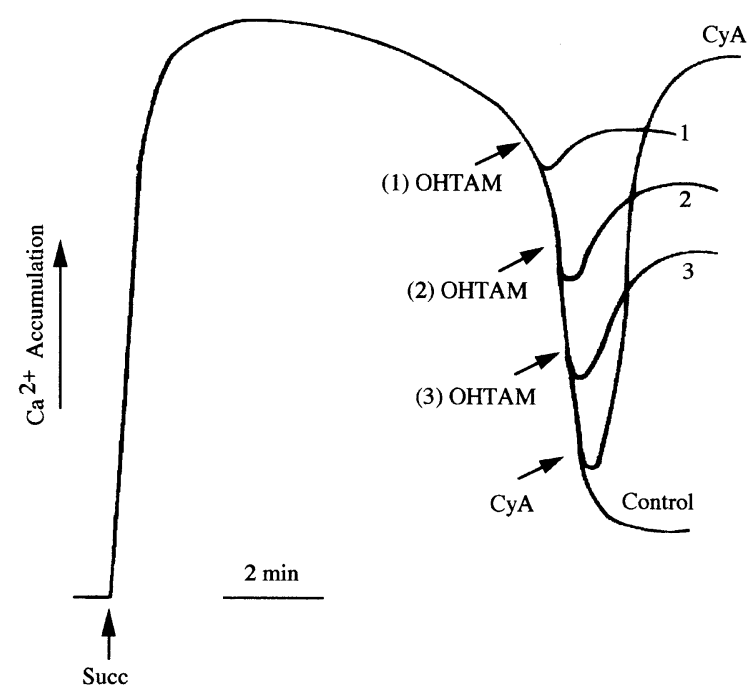

Fig. 6. OHTAM induces $\mathrm{Ca}^{2+}$ re-uptake by mitochondria after MPT induction by $\mathrm{Ca}^{2+}(180 \mathrm{nmol})$ plus $\mathrm{P}_{\mathrm{i}}$. The reactions were carried out as described for Fig. 5 except that OHTAM $(20 \mathrm{nmol} / \mathrm{mg}$ protein) was added at different times during the course of MPT (traces 1-3). The control trace corresponds to $\mathrm{Ca}^{2+}+\mathrm{P}_{\mathrm{i}}$ alone and the trace labeled CyA represents the effect of $1.7 \mathrm{nmol} / \mathrm{mg}$ protein CyA added late during MPT. All the traces are representative of several separate experiments. 

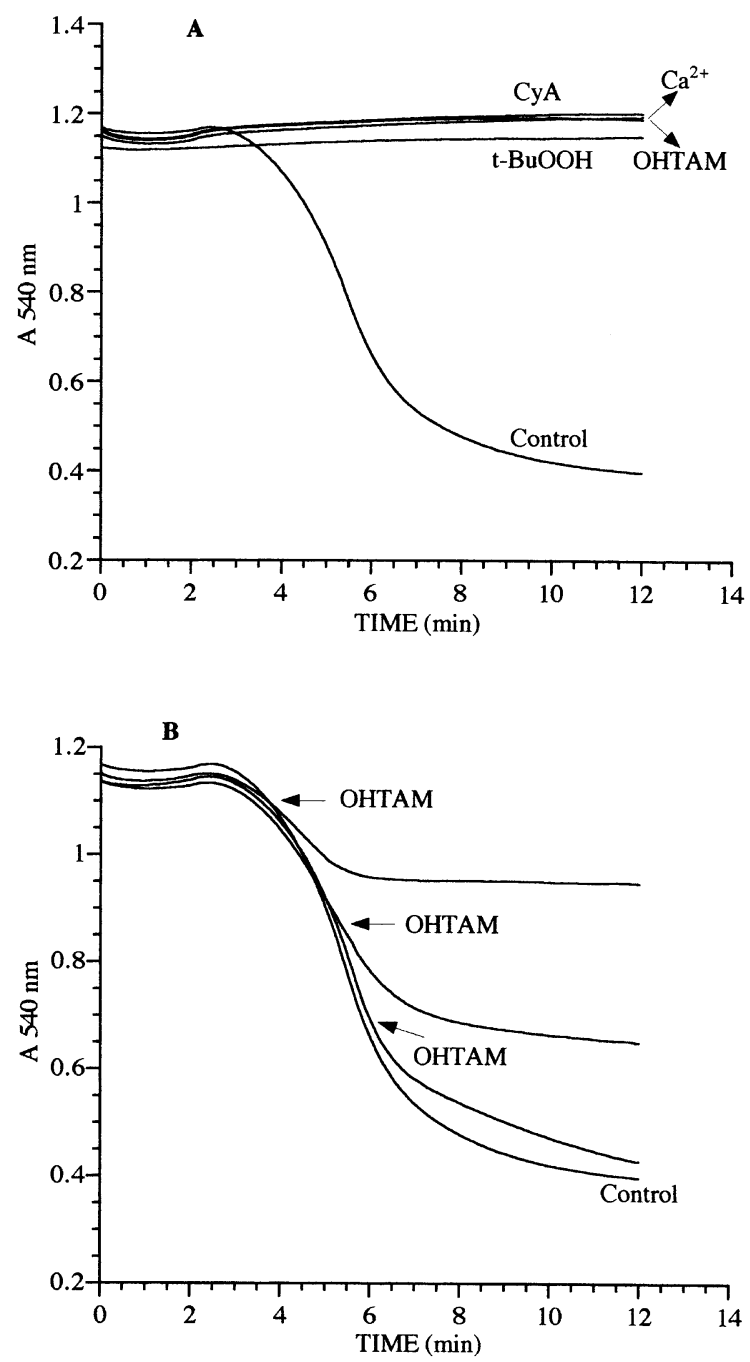

Fig. 7. Inhibitory effect of OHTAM on the MPT induced by $\mathrm{Ca}^{2+}$ plus tert-butylhydroperoxide $(t-\mathrm{BuOOH})$. Succinate-energized mitochondria $(0.5 \mathrm{mg}$ protein $/ \mathrm{ml})$ in $200 \mathrm{mM}$ sucrose, $10 \mathrm{mM}$ Tris-Mops (pH 7.4), 1 mM KH $\mathrm{PO}_{4}, 10 \mu \mathrm{M}$ EGTA supplemented with $2 \mu \mathrm{M}$ rotenone, $0.5 \mu \mathrm{g} / \mathrm{ml}$ oligomycin, at $25^{\circ} \mathrm{C}$, were incubated with $t$-BuOOH $(100 \mu \mathrm{M})$ plus $\mathrm{Ca}^{2+}(100 \mathrm{nmol} / \mathrm{mg}$ protein $)$ in the absence (control) and presence of either OHTAM $(20 \mathrm{nmol} /$ mg protein) (OHTAM) or $1.7 \mathrm{nmol} / \mathrm{mg}$ protein CyA (CyA). Traces of $\left(\mathrm{Ca}^{2+}\right)$ and $(t-\mathrm{BuOOH})$ refer to experiments with $\mathrm{Ca}^{2+}$ or $t$ $\mathrm{BuOOH}$ alone, respectively (A). OHTAM $(20 \mathrm{nmol} / \mathrm{mg}$ protein) was also added at different times after $\mathrm{Ca}^{2+}$ addition to $t$-BuOOH supplemented mitochondria, as indicated by the arrows (B). Light scattering was monitored continuously at $540 \mathrm{~nm}$ for assessing changes in mitochondrial volume. The traces are typical of several independent experiments. tions used to inhibit the MPT affect mitochondrial bioenergetics, the effects of OHTAM on $\Delta \Psi$ and oxygen consumption were evaluated. The concentrations of OHTAM used to inhibit MPT do not affect significantly both $\Delta \Psi$ and the respiratory chain (Fig. 8 ), as evaluated simultaneously with a $\mathrm{TPP}^{+}$or an oxygen-sensitive electrode, respectively, placed in the same closed reaction chamber. Pre-incubation of mitochondria with OHTAM only slightly depresses the total $\Delta \Psi$ developed $(-10 \mathrm{mV})$ (Figs. 8 and 9). Moreover, OHTAM, up to a concentration of either $10 \mathrm{nmol} / \mathrm{mg}$ protein (Fig. 9A) or $20 \mathrm{nmol} / \mathrm{mg}$ protein (Fig. 9B) does not alter significantly state 3 and state 4 respiration, indicating that the respiratory control ratio is not affected by this drug at these concentrations. The phosphorylation efficiency of mitochondria is not also changed since OHTAM does not affect $\Delta \Psi$ fluctuations associated with mitochondrial energiza-

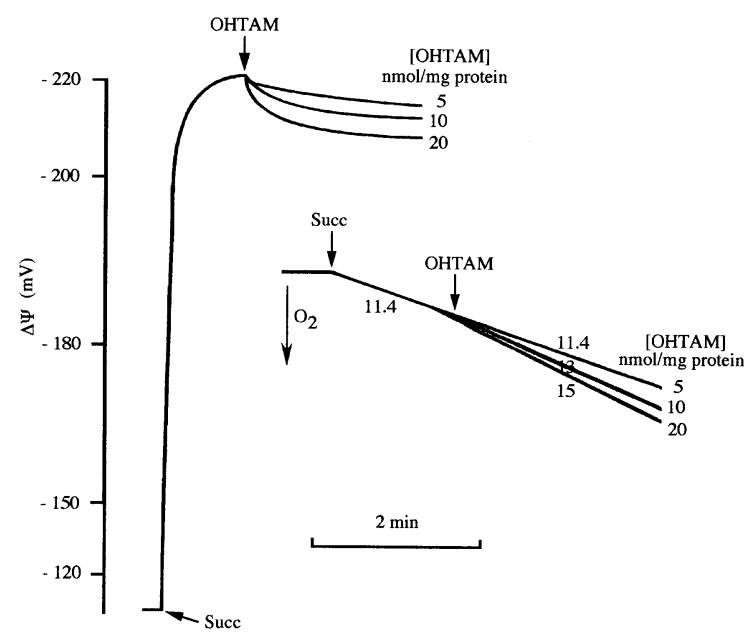

Fig. 8. Effects of OHTAM on $\Delta \Psi$ and state 4 respiration. Mitochondria $(1 \mathrm{mg} / \mathrm{ml})$ were suspended in $130 \mathrm{mM}$ sucrose, $50 \mathrm{mM} \mathrm{KCl}$,

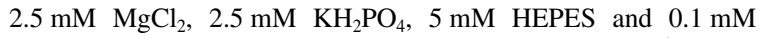
EGTA supplemented with $2 \mu \mathrm{M}$ rotenone and $4 \mu \mathrm{M} \mathrm{TPP}^{+}$. Reactions were conducted at $25^{\circ} \mathrm{C}$ in a closed reaction chamber with constant stirring and experiments were started by adding $5 \mathrm{mM}$ succinate to the mitochondrial suspension. Where indicated 5, 10 or $20 \mathrm{nmol} \mathrm{OHTAM} / \mathrm{mg}$ protein were added after steady-state distribution of $\mathrm{TPP}^{+}$. Mitochondrial respiration rates and $\Delta \Psi$ were evaluated simultaneously using a Clark-type oxygen electrode and a $\mathrm{TPP}^{+}$-selective electrode, respectively, inserted in the same closed reaction chamber. The numbers under or above the traces indicate the rates of $\mathrm{O}_{2}$ consumption. The traces are typical of several independent experiments. 


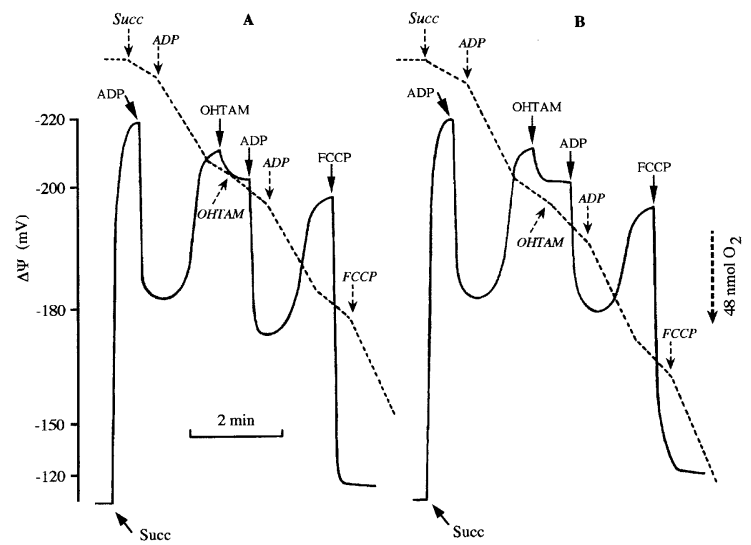

Fig. 9. Effect of OHTAM on mitochondrial respiratory chain (dashed line) and $\Delta \Psi$ (solid line). The reaction was carried out under the similar conditions referred to Fig. 8 . Where indicated 10 (A) or $20 \mathrm{nmol}$ OHTAM/mg protein (B), ADP $(150 \mathrm{nmol})$ and FCCP $(1 \mathrm{nmol} / \mathrm{mg}$ protein) were added. Respiration rates and $\Delta \Psi$ were evaluated simultaneously using a Clark-type electrode and a $\mathrm{TPP}^{+}$-selective electrode, respectively, placed in the same closed reaction chamber. The traces represent typical direct recordings from several independent experiments with different mitochondrial preparations.

tion, phosphorylative cycle induced by ADP or ADP/ O ratio (Fig. 9A,B).

\section{Discussion}

Induction of the $\mathrm{Ca}^{2+}$-dependent MPT has been implicated in several cellular events, namely, in the mitochondrial and cellular $\mathrm{Ca}^{2+}$ homeostasis, in cell defense, apoptotic cell death (Bernardi, 1996) and in the mechanisms of toxic tissue injury (Wallace et al., 1997). It results in a rapid dissipation of electrochemical gradients leading to depolarization of $\Delta \Psi$, mitochondrial swelling, release of low-molecularweight solutes, including $\mathrm{Ca}^{2+}$ and GSH, uncoupling of respiration and inhibition of ATP synthesis (Ichas and Mazat, 1998; Bernardi et al., 1999).

This work demonstrates that OHTAM prevents the $\mathrm{Ca}^{2+}$-dependent swelling (Figs. 1, 2 and 7), membrane depolarization (Fig. 3) and the release of the accumulated $\mathrm{Ca}^{2+}$ (Fig. 5). Also, it affords to mitochondria capacity to recover the $\Delta \Psi$ (Fig. 4) and to sequester some $\mathrm{Ca}^{2+}$ released (Fig. 6), when added during the time course of the reactions. Accord- ingly, OHTAM also prevents mitochondrial swelling when added after energization of mitochondria with succinate and loading with $\mathrm{Ca}^{2+}$ (Figs. 1B and 2), providing evidence that OHTAM neither causes membrane depolarization nor interferes with the $\mathrm{Ca}^{2+}$ uniporter. Moreover, OHTAM does not alter significantly either the $\Delta \Psi$ and state 4 respiration (Fig. 8) or the phosphorylation efficiency of mitochondria (Fig. 9), suggesting that the preventive effects of OHTAM against induction of the MPT are not likely to have a direct effect on the electron transport chain.

Reversible permeabilization of the inner mitochondrial membrane induced by $\mathrm{Ca}^{2+}$ ions plus prooxidants is under the regulatory influence of the redox status of both mitochondrial nucleotides, matrix sulfhydryl groups and membrane protein thiols forming cross-linked protein aggregates (Fagian et al., 1990; Petronilli et al., 1994; Bernardi, 1996; Halestrap et al., 1997). In addition to the oxidation of sulfhydryl groups and nucleotides $[\mathrm{NAD}(\mathrm{P}) \mathrm{H}]$, the generation of reactive oxygen species (ROS) within mitochondria (or a decreasing in their detoxification) contributes to the induction of the MPT, as shown by studies with several MPT inducers, including $t$ BuOOH (Castilho et al., 1996; Nieminen et al., 1995; 1997; Kowaltowski et al., 2000) and $\mathrm{P}_{\mathrm{i}}$ (Kowaltowski et al., 1996, 1998). Moreover, the prooxidants mediated exhaustion of mitochondrial GSH and $\mathrm{NAD}(\mathrm{P}) \mathrm{H}$, lead to the depletion of substrates of the antioxidant enzymes glutathione peroxidases and glutathione reductase, respectively (Valle et al., 1993; Castilho et al., 1996), important components of the mitochondrial antioxidant defense system. $\mathrm{Ca}^{2+}$ and prooxidants seem to play a concerted role in ROS accumulation within mitochondria (Castilho et al., 1996; Byrne et al., 1999). In fact $t$-BuOOH was unable to cause mitochondrial swelling in the absence of $\mathrm{Ca}^{2+}$ (Fig. 7A, $t$-BuOOH), according to what has also been observed by Kushnareva and Sokolove (2000), suggesting that this cation is essential and must act in additional steps in the sequence of events that lead to mitochondrial permeabilization. The binding of $\mathrm{Ca}^{2+}$ to the inner membrane may cause conformational changes to critical proteins that expose thiol groups to the action of oxidants (Fagian et al., 1990; Valle et al., 1993).

Since both $\mathrm{Ca}^{2+}$ plus $\mathrm{P}_{\mathrm{i}}$ and $\mathrm{Ca}^{2+}$ plus $t$-BuOOH- 
induced swelling are dependent on the oxidative stress generated within the mitochondria (Kowaltowski et al., 1996, 2000) and considering that OHTAM is an efficient intramembraneous inhibitor of lipid peroxidation (Custódio et al., 1994), it is reasonable to suggest that OHTAM influences the regulation of the permeability transition by a mechanism related to its incorporation in the membrane and dependent on its antioxidant/scavenging activities (Custódio et al., 1994). In fact, the stronger OHTAM intramembraneous scavenger capacity (Custódio et al., 1994) and partition in biomembranes (Custódio et al., 1991) over TAM parallels its potency against MPT induction [20 nmol OHTAM/mg protein inhibit the MPT whereas the same effect is only observed with $40 \mathrm{nmol} \mathrm{TAM} / \mathrm{mg}$ protein (Custódio et al., 1998)]. Further studies on thiol groups, NAD(P)H and GSH oxidation, already in progress in our laboratory, would help in better elucidating this mechanism of action of OHTAM.

Owing to its antioxidant effects, OHTAM could protect mitochondria from undergoing irreversible permeabilization, a process that leads to the mitochondrial large amplitude swelling and causes the release of factors that activate the apoptogenic catabolic enzymes, due to mechanical disruption of the outer mitochondrial membrane (Skulachev, 1996; Petit et al., 1998). Considering that MPT triggering may cause apoptosis and its inhibition can prevent this process of cell death (Petit et al., 1998), the relevance of MPT inhibition to the OHTAM efficacy as an anticancer drug may be questionable. However, similar to what has been postulated for CyA in induction of lymphoma P388 cell death (Teplova et al., 2000), it is possible that OHTAM might induce tumor cell death as a result of MPT closing, protecting mitochondria from an osmotic shock as a result of periodic decrease in $\Delta \Psi$ and efflux of cations from mitochondria, periodically releasing $\mathrm{Ca}^{2+}$, thus aiding the functioning of mitochondria in the system of spatial transduction of $\mathrm{Ca}^{2+}$ signal in cells.

In conclusion, our data indicate that the MPT inhibition by OHTAM relies on its antioxidant activities since in these concentrations the drug neither affects mitochondrial bioenergetic parameters nor the functions of the mitochondrial $\mathrm{Ca}^{2+}$ uniporter. Moreover, considering that reversible partial openings of MPT in tumor cells can play an essential role in their vital activity in several ways, MPT closing by OHTAM may be implicated in its mechanisms of anticancer action.

\section{Acknowledgements}

This work was supported by the Sapiens Project 99/ 36075/99. Carla M. P. Cardoso is a recipient of a grant from Praxis XXI (Praxis XXI, BD, 21600/99).

\section{References}

Bernardi, P., 1996. The permeabiliy transition pore. Control points of a cyclosporin A-sensitive mitochondrial channel involved in cell death. Biochim. Biophys. Acta 1275, 5-9.

Bernardi, P., Scorrano, L., Colonna, R., Petronilli, V., Di Lisa, F., 1999. Mitochondria and cell death. Mechanistic aspects and methodological issues. Eur. J. Biochem. 264, 687-701.

Borgna, J.-L., Rochefort, H., 1981. Hydroxylated metabolites of tamoxifen are formed in vivo and bound to estrogen receptor in target tissues. J. Biol. Chem. 256, 859-868.

Broekemeier, K.M., Dempsey, M.E., Pfeiffer, D.R., 1989. Cyclosporine $\mathrm{A}$ is a potent inhibitor of the inner membrane permeability transition in liver mitochondria. J. Biol. Chem. 264, 78267830 .

Byrne, A.M., Lemasters, J.J., Nieminen, A-L., 1999. Contribution of increased mitochondrial free $\mathrm{Ca}^{2+}$ to the mitochondrial permeability transition induced by tert-butylhydroperoxide in rat hepatocytes. Hepatology 29, 1523-1531.

Cardoso, C.M.P., Moreno, A.J.M., Almeida, L.M., Custódio, J.B.A., 2000. Hydroxytamoxifen inhibits the mitochondrial permeability transition in vitro. Eur. J. Med. Res. 35, P29.

Castilho, R.F., Kowaltowski, A.J., Vercesi, A.E., 1996. The irreversibility of inner mitochondrial membrane permeabilization by $\mathrm{Ca}^{2+}$ plus prooxidants is determined by the extent of membrane protein thiol cross-linking. J. Bioenerg. Biomembr. 28, 523529.

Ching, C.K., Smith, P.G., Long, R.G., 1992. Tamoxifen-associated hepatocellular damage and agranulocytosis. Lancet 339, 940.

Constantini, P., Chernyak, B.V., Petronilli, V., Bernardi, P., 1996. Modulation of the mitochondrial permeability transition pore by pyridine nucleotides and dithiol oxidation at two separate sites. J. Biol. Chem. 271, 6746-6751.

Cruz Silva, M.M., Madeira, V.M.C., Almeida, L.M., Custódio, J.B.A., 2000. Hemolysis of human erythrocytes induced by tamoxifen is related to disruption of membrane structure. Biochim. Biophys. Acta 1464, 49-61.

Cruz Silva, M.M., Madeira, V.M.C., Almeida, L.M., Custódio, J.B.A., 2001. Hydroxytamoxifen interaction with human erythrocyte membrane and induction of permeabilization and subsequent hemolysis. Toxicol. in Vitro 15, 615-622.

Custódio, J.B.A., Dinis, T.C.P., Almeida, L.M., Madeira, V.M.C., 1991. A reliable and rapid procedure to estimate drug partition- 
ing in biomembranes. Biochem. Biophys. Res. Commun. 176, 1079-1085.

Custódio, J.B.A., Almeida, L.M., Madeira, V.M.C., 1993. The anticancer drug tamoxifen induces changes in the physical properties of model and native membranes. Biochim. Biophys. Acta 1150, 1123-1129.

Custódio, J.B.A., Dinis, T.C.P., Almeida, L.M., Madeira, V.M.C., 1994. Tamoxifen and hydroxytamoxifen as intramembranous inhibitors of lipid peroxidation. Evidence for peroxyl radical scavenging activity. Biochem. Pharmacol. 47, 1989-1998.

Custódio, J.B.A., Moreno, A.J.M., Wallace, K.B., 1998. Tamoxifen inhibits induction of the mitochondrial permeability transition by $\mathrm{Ca}^{2+}$ and inorganic phosphate. Toxicol. Appl. Pharmacol. $152,10-17$.

Davies, A.M., Martin, E.A., Jones, R.M., Lim, C.K., Smith, L.L., White, I.N.H., 1995. Peroxidase activation of tamoxifen and toremifene to cause DNA damage and covalently bound protein adducts. Carcinogenesis 16, 539-545.

Estrabrook, R.W., 1967. Mitochondrial respiratory control and the polarographic measurement of ADP/O ratios. Methods Enzymol. 10, 41-47.

Fagian, M.M., Pereira-da-Silva, L., Martins, I.S., Vercesi, A., 1990. Membrane protein thiol cross-linking associated with the permeabilization of the inner mitochondrial membrane by $\mathrm{Ca}^{2+}$ plus prooxidants. J. Biol. Chem. 265, 19955-19960.

Fisher, B., Costantino, J.P., Redmond, C.K., Fisher, E.R., Wickerham, D.L., Cronin, W.M., NSABP Contributors, 1994. Endometrial cancer in tamoxifen-treated breast cancer patients: findings from the National Surgical Adjuvant Breast and Bowel Project (NSABP) B-14. J. Natl. Cancer Inst. 86, 527537.

Gornall, A.G., Bardawill, C., David, M.M., 1949. Determination of serum proteins by means of the biuret reaction. J. Biol. Chem. 177, 751-756.

Halestrap, A.P., Wodfield, K-Y., Connern, C.P., 1997. Oxidative stress thiol reagents and membrane potential modulate the mitochondrial permeability transition by affecting nucleotide binding to the adenine nucleotide translocase. J. Biol. Chem. 272, 3346-3354.

Ichas, F., Mazat, J.-P., 1998. From calcium signalling to cell death: two conformations for the mitochondrial permeability transition pore. Switching from low- to high-conductance state. Biochim. Biophys. Acta 1366, 33-50.

Jordan, V.C., 1990. Long-term adjuvant tamoxifen therapy for breast cancer. Breast Cancer Res. Treat. 15, 125-136.

Kamo, N., Maratsugu, M., Hongoh, R., Kobatake, V., 1979. Membrane potential of mitochondria measured with an electrode sensitive to tetraphenilphosphonium and relationship between proton electrochemical potential and phosphorylation potential in steady state. J. Memb. Biol. 49, 105-121.

Kargacin, M.E., Ali, Z., Ward, C.A., Pollock, N.S., Kargacin, G.J., 2000. Tamoxifen inhibits $\mathrm{Ca}^{2+}$ uptake by the cardiac sarcoplasmic reticulum. Eur. J. Physiol. 440, 573-579.

Kemp, J.V., Adam, H.K., Wakeling, A.E., Slater, R., 1983. Identification and biological activity of tamoxifen metabolites in human serum. Biochem. Pharmacol. 32, 2045-2052.

Kowaltowski, A.J., Castilho, R.F., Grijalba, M.T., Vercesi, A.,
1996. Opening of the mitochondrial permeability transition pore by uncoupling or inorganic phosphate in the presence of $\mathrm{Ca}^{2+}$ is dependent on mitochondrial-generated reactive oxygen species. FEBS Lett. 378, 150-152.

Kowaltowski, A.J., Netto, L.E.S., Vercesi, A.E., 1998. The thiolspecific antioxidant enzyme prevents mitochondrial permeability transition. Evidence for the participation of reactive oxygen species. J. Biol. Chem. 273, 12766-12769.

Kowaltowski, A.J., Vercesi, A.E., Fiskum, G., 2000. Bcl-2 prevents mitochondrial permeability transition and cytochrome $\mathrm{c}$ release via maintenance of reduced pyridine nucleotides. Cell Death Differ. 7, 903-910.

Kushnareva, Y.E., Sokolove, P.M., 2000. Prooxidants open both the mitochondrial permeability transition pore and a low-conductance channel in the inner mitochondrial membrane. Arch. Biochem. Biophys. 376, 377-388.

Lien, E.A., Ueland, P.M., Solheim, E., Kvinnsland, S., 1987. Determination of tamoxifen and four metabolites in serum by lowdispersion liquid chromatography. Clin. Chem. 33, 1608-1614.

Lien, E.A., Solheim, E., Ueland, P.M., 1991. Distribution of tamoxifen and its metabolites in rat and human tissues during steadystate treatment. Cancer Res. 51, 4837-4844.

MacCallum, J., Cummings, J., Dixon, J.M., Miller, W.R., 1996. Solid-phase extraction and high-performance liquid chromatographic determination of tamoxifen and its major metabolites in plasma. J. Chromatogr. B 678, 317-323.

Madeira, V.M.C., 1975. A rapid and ultrasensitive method to measure $\mathrm{Ca}^{2+}$ movements across biological membranes. Biochem. Biophys. Res. Commun. 64, 870-876.

Mauvais-Jarvis, P., Baudot, N., Castaigne, D., Banzet, P., Jutten, F., 1986. Trans-4-hydroxytamoxifen concentration and metabolism after local percutaneous administration to human breast. Cancer Res. 46, 1521-1525.

McCague, R., Parr, I.B., Leclercq, G., Leung, O.-T., Jarman, M., 1990. Metabolism of tamoxifen by isolated rat hepatocytes. Identification of the glucuronide of 4-hydroxytamoxifen. Biochem. Pharmacol. 39, 1459-1465.

Moreno, A.J., Madeira, V.M.C., 1991. Mitochondrial bioenergetics as affected by DDT. Biochim. Biophys. Acta 1060, 166-174.

Nieminen, A-L., Saylor, A.K., Tesfai, S.A., Herman, B., Lemasters, J., 1995. Contribution of the mitochondrial permeability transiton to lethal injury after exposure of hepatocytes to $t$-butylhydroperoxide. Biochem. J. 307, 99-106.

Nieminen, A.-L., Byrne, A.M., Herman, B., Lemasters, J., 1997. Mitochondrial permeability transiton in hepatocytes induced by $t$-BuOOH: $\mathrm{NAD}(\mathrm{P}) \mathrm{H}$ and reactive oxygen species. Am. J. Physiol. 272, C1286-C1294.

Petit, X.P., Goubern, M., Diolez, P., Susin, A.S., Zamzami, N., Kroemer, G., 1998. Disruption of the outer mitochondrial membrane as a result of large amplitude swelling: the impact of irreversible permeability transition. FEBS Lett. 426, 111-116.

Petronilli, V., Constantini, P., Scorrano, L., Colonna, R., Passamonti, S., Bernardi, P., 1994. The voltage sensor of the mitochondrial permeability transition pore is tuned by the oxidation-reduction state of vicinal thiols. J. Biol. Chem. 269, 16638-16642.

Pujol, H., Girault, J., Rouanet, P., Fournier, S., Grenier, J., Simony, J., Fourtillan, J.-B., Pujol, J.-L., 1995. Phase I study of percuta- 
neous 4-hydroxytamoxifen with analyses of 4-hydroxytamoxifen concentrations in breast cancer and normal breast tissue. Cancer Chemother. Pharmacol. 36, 493-498.

Sauvez, F., Drouin, D.S., Attia, M., Bertheux, H., Forster, R., 1999. Cutaneously applied 4-hydroxytamoxifen is not carcinogenic in female rats. Carcinogenesis 20, 843-850.

Skulachev, V.P., 1996. Why are mitochondria involved in apoptosis? FEBS Lett. 397, 7-10.

Suwalsky, M., Hernandez, P., Villena, F., Aguilar, F., Sotomayor, C.P., 1998. Interaction of the anticancer drug Tamoxifen with the human erythrocyte membrane and molecular models. $\mathrm{Z}$. Naturforsh. (C) 53, 182-190.

Teplova, V., Evtodienko, Y., Odinokova, I., Kruglov, A., Kudrjavtsev, A., 2000. Suppression of mitochondrial permeability transition pore and induction of lymphoma P388 cell death by cyclosporin A. Life 50, 75-80.
Valle, V.G.R., Fagian, M.M., Parentoni, L.S., Meinicke, A.R., Vercesi, A.E., 1993. The participation of reactive oxygen species and protein thiols in the mechanism of mitochondrial inner membrane permeabilization by calcium plus prooxidants. Arch. Biochem. Biophys. 307, 1-7.

Wallace, K.B., Eells, J.T., Madeira, V.M.C., Cortopassi, G., Jones, D.P., 1997. Mitochondria-mediated cell injury. Fundam. Appl. Toxicol. 38, 23-37.

Wallace, K.B., Starkov, A.A., 2000. Mitochondrial targets of drug toxicity. Annu. Rev. Pharmacol. Toxicol. 40, 353-388.

Williams, G.M., Iatroploulos, M.J., Djordjevic, M.V., Kaltenberg, O.P., 1993. The tryphenylethylene drug tamoxifen is a strong liver carcinogen in the rat. Carcinogenesis 14, 315-317.

Zoratti, M., Szabo, I., 1995. The mitochondrial permeability transition. Biochim. Biophys. Acta. 1241, 139-176. 